\title{
Studies on the procurement of blood coagulation factor VIII: effects of plasma freezing rate and storage conditions on cryoprecipitate quality
}

\author{
A FARRUGIA, ${ }^{*}$ C PROWSE \\ From the Edinburgh and South-East Scotland Blood Transfusion Service, Royal Infirmary, Edinburgh
}

SUMMARY Plasma was frozen and stored in different ways before processing to cryoprecipitate by a standard thawing technique. Freezing rate was found to be important with slow freezing having a deleterious effect on cryoprecipitate quality. Storage of frozen plasma at constant temperatures for periods up to six months had no effect on the quality of cryoprecipitate, with no difference being found for plasma stored at $-20^{\circ} \mathrm{C}$ or $-40^{\circ} \mathrm{C}$. Subjecting frozen plasma to deliberate temperature fluctuations resulted in a considerable increase in the amount of fibrinogen recovered in cryoprecipitate, with the factor VIII yield being relatively unaffected.

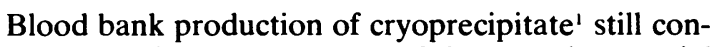
stitutes an important source of therapeutic material for treatment of haemophilia, ${ }^{23}$ while bulk cryoprecipitation is the preliminary step in $98 \%$ of the world's production of factor VIII concentrate. ${ }^{4}$ Any factors influencing the quality of cryoprecipitation thus have an important bearing on the logistics of haemophilia care. Several studies have established that fast plasma thawing in a low temperature waterbath results in higher factor VIII yields than the original overnight thaw in air. ${ }^{5-8}$ The introduction by Mason' of a modified form of fast plasma thawing, in which thawed supernatant plasma was siphoned over leaving the cryoprecipitate in the original plastic pack, further optimised this aspect of cryoprecipitate production. This method results in factor VIII yields of $70 \%$ compared with $40 \%$ using other techniques,' but it is labour intensive and considered by some to be too cumbersome to allow routine production. ${ }^{10}$

Although much data has been published regarding thawing methods, uncertainty exists about the optimal way of freezing plasma. Placement of fresh plasma packs in $\mathrm{a}-30^{\circ} \mathrm{C}$ or $-20^{\circ} \mathrm{C}$ freezer has been reported to lead to decreased factor VIII yields in cryoprecipitate compared with plasma frozen faster in blast freezers." ${ }^{12}$ Placement in $-40^{\circ} \mathrm{C}$ freezers has been reported to give yields similar to faster

\section{Accepted for publication 12 December 1984}

*Present address: Blood Transfusion Unit, Pathology Department, St Luke's Hospital, Gwardamanga, Malta. freezing techniques such as $-80^{\circ} \mathrm{C}$ blast freezers or placement in liquid nitrogen. ${ }^{126}$

Storage of frozen plasma before processing to cryoprecipitate is another aspect that has received little attention. Although early studies suggested that plasma factor VIII clotting activity (VIII:C) is labile at $-20^{\circ} \mathrm{C}$, subsequent work, using more reliable assays, reported no loss in VIII: $\mathrm{C}$ for periods of up to 20 months at $-20^{\circ} \mathrm{C} .^{1314} \mathrm{As}$ far as production of cryoprecipitate goes, however, VIII:C is not the only parameter of importance; changes in other proteins have been reported to occur during frozen plasma storage and to result in processing difficulties during subsequent production of cryoprecipitate and factor VIII concentrate. ${ }^{15}$

In this study a modification of the thaw-siphon technique $^{16}$ has been used to study the effects of plasma freezing rate and storage conditions on cryoprecipitate yield and purity.

\section{Material and methods}

Plasma used in this study was prepared from normal citrate phosphate dextrose blood donations within $3 \mathrm{~h}$ of donation. Plasma pools of six donations were used in each experiment to avoid the variations in VIII:C content found in different individuals. ${ }^{8}$ The plasma was pooled in a 21 pack and aliquots of $200 \mathrm{ml}$ were distributed into $300 \mathrm{ml}$ Fenwall R2011 transfer packs. The plasma was then frozen and stored as described below in one of two ways. Either all packs were subjected to fast freezing and then 
aliquots stored at $-20^{\circ} \mathrm{C}$ or $-40^{\circ} \mathrm{C}$ and processed to cryoprecipitate at $16 \mathrm{~h}$, three months, or six months; or three packs from each pool were used to study the effect of freezing rate. These packs were further used to study the effect of temperature insult during storage (fast frozen units) and time of frozen storage (slow frozen units). For each comparison six distinct plasma pools were used. Statistical analysis was based only on results obtained from such split pools processed as follows.

\section{SLOW FREEZING}

Packs of plasma were placed in thin aluminium cassettes and placed in a $-40^{\circ} \mathrm{C}$ cabinet freezer. The cassettes were placed vertically and the packs had the outlet ports down.

\section{FAST FREEZING}

Packs were placed in cassettes as above but were frozen in a $-70^{\circ} \mathrm{C}$ ethanol bath which had been cooled using liquid nitrogen or solid carbon dioxide.

\section{FREEZING RATES}

For both these freezing techniques, plasma temperature was monitored with a thermocouple (Comark Instruments) placed in the middle of a pack, which was connected to a pen recorder (Vitatron).

\section{STORAGE STUDIES}

Plasma pools prepared as above were frozen in $-70^{\circ} \mathrm{C}$ ethanol or $-40^{\circ} \mathrm{C}$ air and stored at different temperatures and for different time periods as described in the Results section. Daily checks ensured that the storage temperatures were within reasonable limits $\left( \pm 4^{\circ} \mathrm{C}\right)$ of the temperatures stated. In studies involving temperature insult plasma packs frozen to $-70^{\circ} \mathrm{C}$ were subjected to deliberate fluctuations in temperature by placing at $+4^{\circ} \mathrm{C}$ until the core temperature reached $-5^{\circ} \mathrm{C}$.

\section{CRYOPRECIPITATE PREPARATION}

This was as described by Mason et al ${ }^{16}$ with some modifications. Instead of the tensioning device described by Mason et al, elastic bands were stretched between metallic rods placed through the slits in the packs' lateral edges so as to maintain the shape of the pack during thawing. On completion of thawing, the cryoprecipitate was dissolved at $37^{\circ} \mathrm{C}$ in its own residual supernatant plasma and samples of cryoprecipitate and cryosupernatant were stored at $-40^{\circ} \mathrm{C}$ for subsequent assay.

Factor VIII:C was assayed using a one stage clotting assay, ${ }^{17}$ factor VIII coagulant antigen (VIII:$\mathrm{CAg})$ was assayed immunoradiometrically, ${ }^{18}$ and factor VIII related antigen (VIIIR:Ag) was determined by electroimmunoassay, ${ }^{17}$ except for samples of cryosupernatant plasma, which were assayed immunoradiometrically. ${ }^{19}$ Fibrinogen was assayed by electroimmunoassay ${ }^{17}$ and total protein by the Biuret method. ${ }^{20}$

Results are shown as mean $\pm \mathrm{SD}$. Statistical analysis was by the paired $t$ test.

\section{Resuits}

Fig. 1 shows the temperature profiles of plasma packs frozen under the two different sets of conditions studied. The average cooling rates were $-5^{\circ} \mathrm{C} /$ minute and $-0.33^{\circ} \mathrm{C} /$ minute for fast and slow frozen plasma respectively. Plasma frozen under these conditions was processed to cryoprecipitate after overnight storage at $-40^{\circ} \mathrm{C}$. It was immediately noticeable that plasma frozen slowly produced a steady flux of particulate material in the siphon lines during thawing. On the other hand, fast frozen plasma produced a clear supernatant with no particles, unless thawing was allowed to proceed until the residual cryoprecipitate also siphoned over. Fig. 2 shows that slow freezing resulted in a slightly lower recovery of total VIII: C (expressed as the sum of the VIII:C recovered in cryoprecipitate and cryosupernatant) on thawing the plasma; this difference was not significant $(p>0 \cdot 1)$. In slowly frozen plasma, however, only $47 \%$ of the residual VIII:C was recovered in the cryoprecipitate after thawing. This poor cryoprecipitability of factor VIII in slowly frozen plasma was confirmed by assays of other factor VIII related activities in cryoprecipitate and cryosupernatant (Fig. 2). Fast frozen plasma gave much better results: 425 units of VIII:C/ $\mathrm{kg}$ plasma was recovered in cryoprecipitate compared with 318 units $/ \mathbf{k g}$ for slowly frozen plasma $(p<0 \cdot 05)$. Plasma frozen fast also gave yields of fibrinogen in cryoprecipitate of $824 \mathrm{mg} / \mathrm{kg}$ plasma, compared with 522

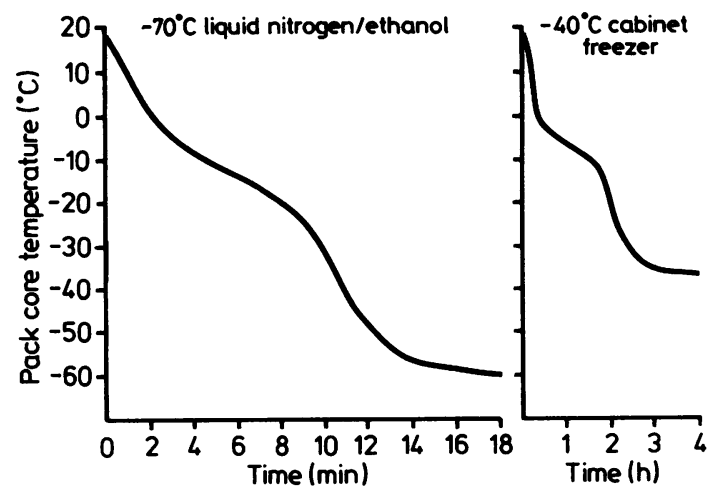

Fig. 1 Temperature recorded in plasma packs frozen in different media. 


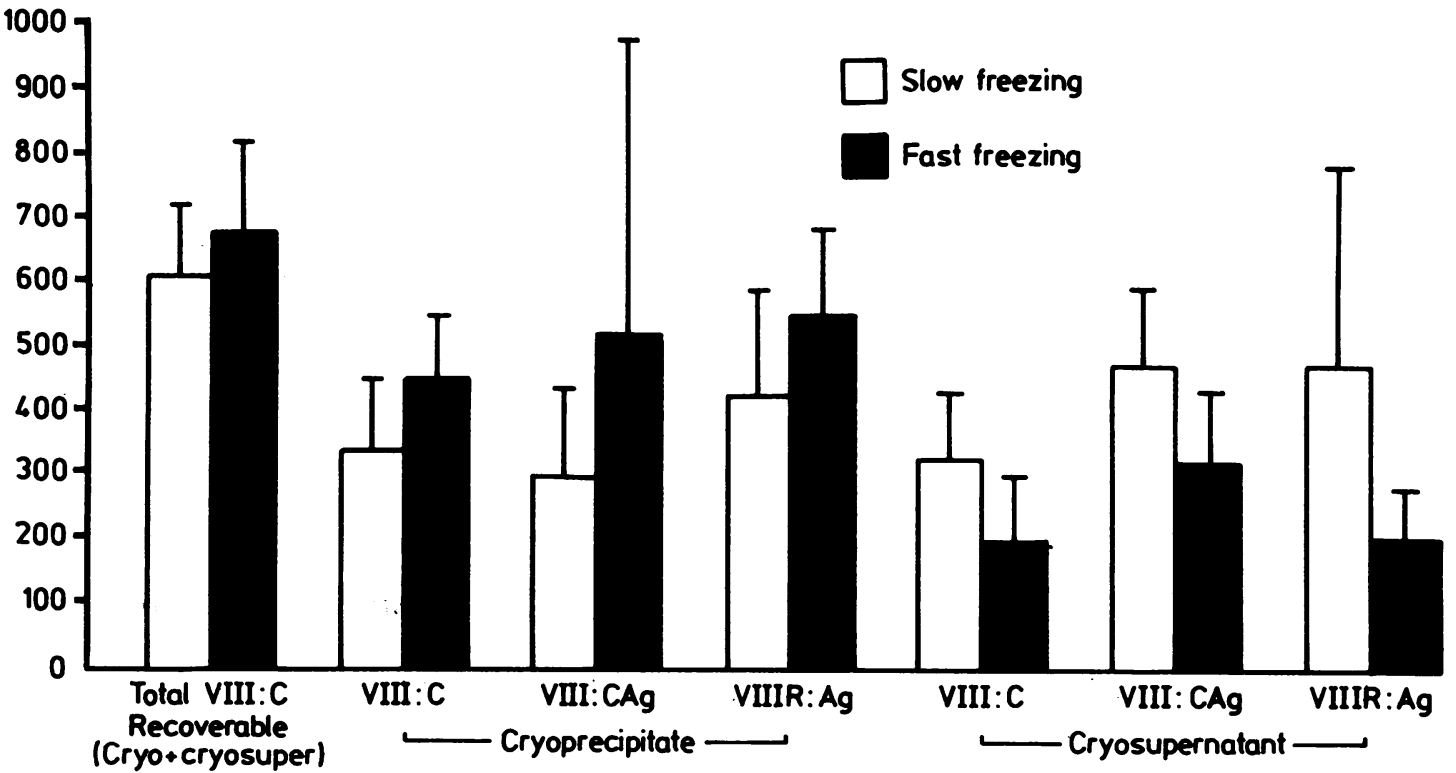

Fig. 2 Distribution of factor VIII related activities in plasma fractions derived from plasma frozen at different rates. Mean $\pm S D$ of six experiments expressed as U/kg of starting plasma.

$\mathrm{mg} / \mathrm{kg}$ for slowly frozen plasma $(\mathrm{p}=\mathbf{0 \cdot 0 1})$. The appearance of particulate material during thawing, as well as the higher levels of factor VIII related activities in the cryosupernatant derived from slowly frozen plasma, suggests that cryoprecipitate from such plasma is not efficiently retained during the thawing process and is lost in the supernatant during siphoning.

The Table summarises data on plasma frozen in different ways and stored under constant temperatures for different periods. Data for fast frozen plasma in this series of experiments are based on distinct plasma pools from those used for the freez- ing rate experiments shown in Fig. 2. As long as constant temperature was maintained, there was no significant difference in cryoprecipitate factor VIII and fibrinogen for plasma stored at $-20^{\circ} \mathrm{C}$ and $-40^{\circ} \mathrm{C}$; storage of plasma for up to six months at either temperature also had no deleterious effect. While there is some suggestion of reduced yields in cryoprecipitate prepared from plasma stored frozen for six months, it would be necessary to compare a large number of plasma pools to establish if this is significant.

Fig. 3 shows the temperature fluctuations that were recorded in the core of a plasma pack sub-

Table Effects of plasma freezing and storage temperature on factor VIII:C and fibrinogen yield in cryoprecipitate

\begin{tabular}{|c|c|c|c|c|c|}
\hline $\begin{array}{l}\text { Freezing } \\
\text { rate }\end{array}$ & $\begin{array}{l}\text { Period of } \\
\text { storage }\end{array}$ & $\begin{array}{l}\text { Temperature } \\
\text { of storage } \ddagger\end{array}$ & $\begin{array}{l}\text { Total VIII:C } \\
\text { recovered (precipitate } \\
+ \text { supermatant) } \\
\text { (U/kg plasma) }\end{array}$ & $\begin{array}{l}\text { VIII:C } \\
\text { precipitate yield } \\
\text { (U/kg plasma })\end{array}$ & $\begin{array}{l}\text { Fibrinogen } \\
\text { precipitate yield } \\
\text { (mg/kg plasma) }\end{array}$ \\
\hline Fast* & $\begin{aligned} 16 \mathrm{~h} \\
3 \mathrm{mo} \\
6 \mathrm{mo} \\
16 \mathrm{~h} \\
3 \mathrm{mo} \\
6 \mathrm{mo} \\
16 \mathrm{~h} \\
3 \mathrm{mo}\end{aligned}$ & $\begin{array}{l}-20^{\circ} \mathrm{C} \\
-20^{\circ} \mathrm{C} \\
-20^{\circ} \mathrm{C} \\
-40^{\circ} \mathrm{C} \\
-40^{\circ} \mathrm{C} \\
-40^{\circ} \mathrm{C} \\
-40^{\circ} \mathrm{C} \\
-40^{\circ} \mathrm{C}\end{array}$ & $\begin{array}{l}623 \pm 108 \\
698 \pm 123 \\
690 \pm 82 \\
698 \pm 125 \\
718 \pm 102 \\
730 \pm 101 \\
610 \pm 101 \\
611 \pm 183\end{array}$ & $\begin{array}{l}426 \pm 80 \\
500 \pm 118 \\
416 \pm 67 \\
493 \pm 116 \\
522 \pm 77 \\
449 \pm 47 \\
318 \pm 111 \\
306 \pm 62\end{array}$ & $\begin{array}{l}605 \pm 172 \\
609 \pm 187 \\
538 \pm 115 \\
607 \pm 292 \\
577 \pm 51 \\
542 \pm 47 \\
522 \pm 270 \\
502 \pm 79\end{array}$ \\
\hline
\end{tabular}

$*-70^{\circ} \mathrm{C}$ liquid $\mathrm{N}_{2}$ /ethanol.

$+-40^{\circ} \mathrm{C}$ deep freeze.

$¥$ Achieved by placement in deep freezes of the appropriate temperature. Results show mean \pm SD for six different experiments, each using a pool of six donations, aliquots of which were treated in the different ways described. Distinct sets of pools were used for the fast freezing and slow freezing experiments and these results are thus not directly comparable. Fig. 2 shows the results of studies designed to test the effect of freezing rate. 


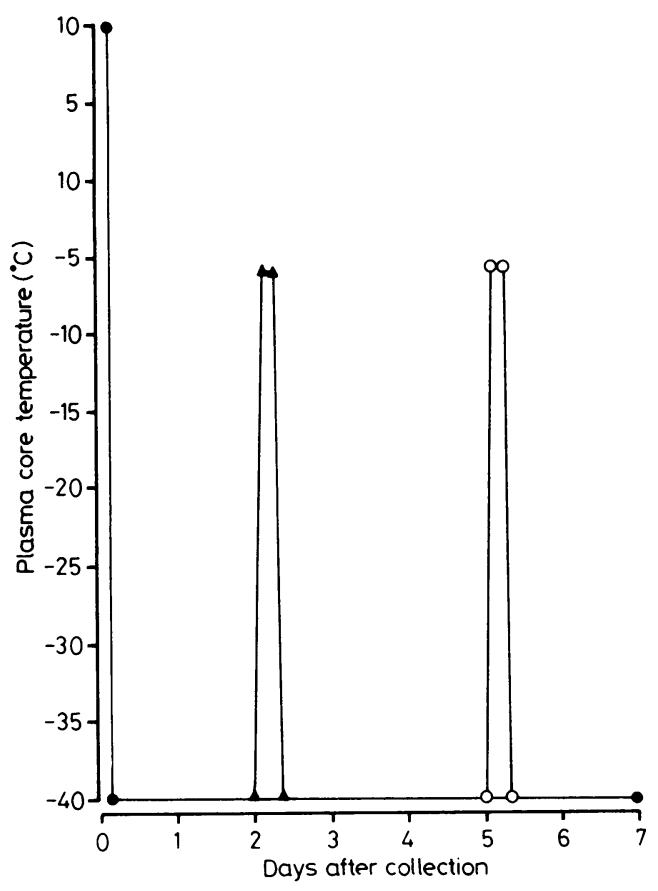

Fig. 3 Temperature recorded in a plasma pack subjected to temperature insult. Control: frozen in liquid nitrogen/ethanol to $-40^{\circ} \mathrm{C}$ and held at $-40^{\circ} \mathrm{C}$ for seven days (๑). Insulted once by warming to $-5^{\circ} \mathrm{C}$ on day 2 and then replaced in $-40^{\circ} \mathrm{C}$ storage $(\Delta)$. Insulted twice after two and five days $(\mathrm{O})$.

jected to the temperature insult described. Fig. 4 shows the effect of these fluctuations on the constituents of cryoprecipitate produced from such plasma. Warming and recooling frozen plasma resulted in a $20 \%$ drop in the total recoverable VIII:C. This was reflected by a fall in cryosupernatant VIII:C levels $(p<0.05)$, rather than in a decreased cryoprecipitate VIII:C yield. The fibrinogen content of cryoprecipitate was affected by temperature fluctuations: insulted plasma yielded twice as much cryoprecipitate fibrinogen $(p<0.01$; Fig. 4b) with a resultant fall in the specific activity of cryoprecipitate VIII:C (expressed as $\mathrm{U} / \mathrm{mg}$ of fibrinogen). A second cycle of temperature insult produced no further significant change in fibrinogen content. The difference between mean fibrinogen yield in cryoprecipitate in this study and in the previous one on the effect of freezing rate and storage temperature emphasises the value of using split plasma pools when comparing the effect of different processing variables.

\section{Discussion}

In this study a standard thaw-siphon method was used to produce cryoprecipitate. The original method described by Mason results in considerable improvements in cryoprecipitate factor VIII yield." In the modified method described subsequently, ${ }^{16}$ and used in this study, some of this increased yield is sacrificed to obtain improved purity. Thus, while a specific activity of $0.09 \mathrm{U} / \mathrm{mg}$ total protein is achieved using conventional thaw-siphoning, ${ }^{7}$ the modified technique gives up to $0.5 \mathrm{U} / \mathrm{mg} .{ }^{16}$ In the present study, a specific activity of $0.19 \mathrm{U} / \mathrm{mg}$ was achieved, which is lower than found by Mason et al, possibly as a result of less efficient tensioning leading to retention of excess plasma protein with the cryoprecipitate. As has been pointed out previously, ${ }^{8}$ the use of split plasma pools in comparing different modes of cryoprecipitate production is essential. While differences in the assay and processing of various pools are, to some extent, unavoidable, these were minimised in the present study by using well characterised established techniques.

Previous studies ${ }^{717}$ using the thaw-siphon technique all used plasma frozen by fast freezing methods. The importance of fast freezing is confirmed by the present study. Placement of plasma in a $-40^{\circ} \mathrm{C}$ freezer, a method found to be adequate for plasma processed by conventional fast
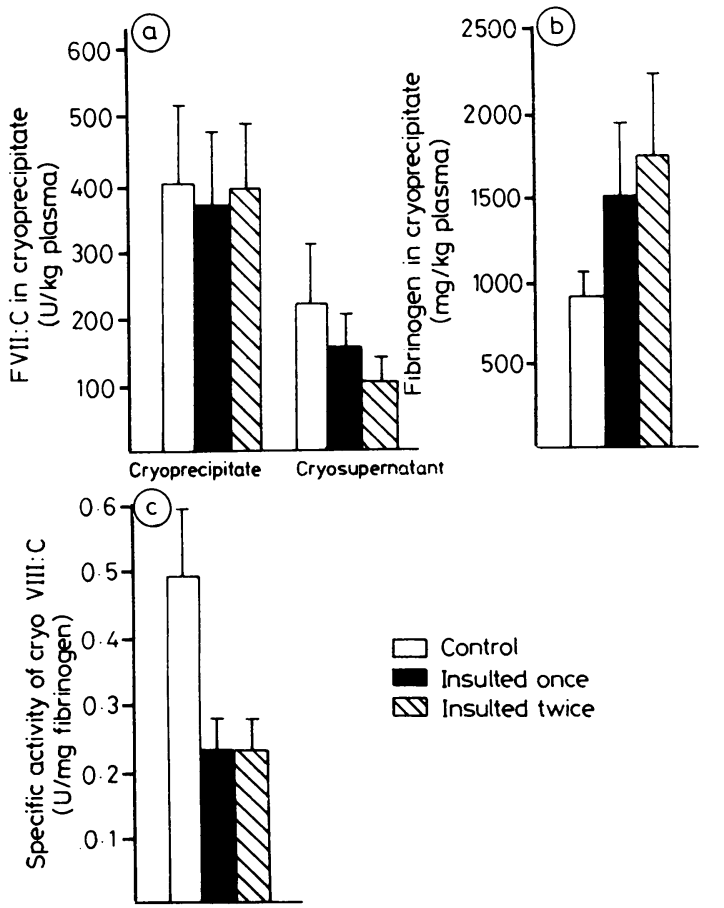

Fig. 4 Effect of temperature insult (warming and refreezing) on cryoprecipitate preparation. Mean and $S D$ for six experiments. All units were processed to cryoprecipitate seven days after initial plasma freezing. (a) Yield of VIII:C in plasma fractions. (b) Yield of fibrinogen in cryoprecipitate. (c) Specific activity of VIII:C (U/mg fibrinogen) in cryoprecipitate. 
thawing, ${ }^{612}$ resulted in decreased yields of factor VIII related activities and of fibrinogen in cryoprecipitate. Particulate matter was observed as soon as slowly frozen plasma started thawing, and this phenomenon was accompanied by a loss of factor VIII related activities to the supernatant. This suggests that cryoprecipitate formation and harvesting depends on the mode of freezing. Fast freezing is necessary for optimal yields of factor VIII, at least by the technique used here.

Within the limits tested, the storage time or temperature of frozen plasma did not affect cryoprecipitate quality, so long as steady storage conditions were maintained. The finding that $-20^{\circ} \mathrm{C}$ is adequate is important as storage at this temperature is much less expensive than at colder temperatures. Although it has been suggested that storage below the eutectic point is to be preferred, ${ }^{21}$ no evidence for this was found in the time scale of the present study. Deliberate temperature insult during storage, however, had a pronounced effect on cryoprecipitate quality. Although VIII:C yields in cryoprecipitate from insulted plasma were not severely affected, the total amount of VIII:C recoverable declined by $20 \%$ owing to a sharp drop in the VIII: $C$ recovered in cryosupernatant. The increased lability of cryosupernatant VIII:C compared with cryoprecipitate VIII:C has been documented ${ }^{22}$ and it seems that the deleterious effects of temperature insult result in loss of cryosupernatant VIII:C activity. The striking increase in cryoprecipitate fibrinogen that results from temperature insult may be one of the reasons for the variation in cryoprecipitate mass that has been noted during plasma fractionation. ${ }^{523}$ Temperature fluctuations such as those deliberately engineered in the present study may occur during storage and transportation of bulk frozen plasma, although warming of large plasma blocks is bound to be less rapid than for the smaller blocks used in the present study. Increased cryoprecipitate fibrinogen is responsible for difficulties in extracting and further processing factor VIII concentrate and may result in poor filterability and solubility. The storage temperature profile is thus an important variable in determining the quality of plasma destined for fractionation to factor VIII products.

AF was a recipient of a British Council Grant (MLT/81/01) during the course of this study and was on study leave from the Blood Transfusion Unit, St Luke's Hospital, Malta.

\section{References}

' Pool JG, Shannon AE. Production of high potency concentrates of antihaemophilic globulin in a closed-bag system; assay in vitro and in vivo. $N$ Engl $J$ Med 1965;273:1443-7.

${ }^{2}$ Rizza CR, Spooner RJD. Treatment of haemophilia and related disorders in Britain and Northern Ireland during 1976-80: report on behalf of the directors of haemophilia centres in the United Kingdom. Br Med J 1983;286:929-3.

${ }^{3}$ Aledort JM. Current concepts in diagnosis and management of haemophilia. Hosp Prac 1982;17:77-92.

${ }^{4}$ De Vreker RA. The fractionator's point of view. Scand J Haematol 1980;suppl:35.

${ }^{5}$ Brown DL, Hardisty RM, Koroy MH, Bracken C. Antihaemophilic globulin: preparation by an improved cryoprecipitation method and clinical use. $\mathrm{Br}$ Med J 1967;ii:79-85.

- Vermeer C, Soute BAM, Ates G, Brummelhuis HGJ. Contributions to the optimal use of human blood. VII. Increase in the yield of factor VIII in four-donor cryoprecipitate by an improved processing of blood and plasma. Vox Sang 1976;30:1-22.

'Prowse C, McGill A. Evaluation of the "Mason" (continuousthaw-siphon) method for cryoprecipitate production. Vox Sang 1979;37:235-43.

" Wensley RT, Snape J. Preparation of improved cryoprecipitated factor VIII concentrate. A controlled study of three variables affecting the yield. Vox Sang 1980;38:222-8.

- Mason EC. Thaw-siphon technique for production of cryoprecipitate concentrate of factor VIII. Lancet 1978;ii:15-9.

${ }^{10}$ Smit Sibinga C Th, Das PC. Heparin and factor VIII. Scand $J$ Haematol 1984;40 (suppl): 111-22.

" Slichter SJ, Counts RB, Henderson R, Harker LA. Preparation of cryoprecipitated factor VIII concentrates. Transfusion 1976; 16:616-26.

${ }_{12}$ Rock GA, Tittley $P$. The effect of temperature variations on cryoprecipitate. Transfusion 1979;19:86-9.

${ }^{13}$ Penick GD, Brinkhous RM. Relative stability of plasma antihaemophilic factor (AHF) under different conditions of storage. Am J Med Sci 1956:434-41.

14 Pool JG, Robinson J. Observations on plasma banking and transfusion procedures for haemophilic patients using a quantitative assay for antihaemophilic globulin (AHF). Br J Haematol 1959;5:24-30.

is Newman J, Johnson AJ, Karpatkin M, Puszkin S. Methods for the production of clinically effective intermediate and high purity factor VIII concentrate. Br J Haematol 1971;21:1-20.

${ }^{10}$ Mason EC, Pepper DS, Griffin B. Production of cryoprecipitate of intermediate purity in a closed system thaw-siphon process. Thromb Haemostas 1981;46:543-6.

${ }^{17}$ Chirnside A, Urbaniak SJ, Prowse CV, Keller AJ. Coagulation abnormalities following intensive plasma exchange on the cell separator. II. Effects on factor I, II, V, VII, IX, X and antithrombin III. Br J Haematol 1981;48:627-34.

${ }^{18}$ Rotblat F, Tuddenham EGD. Immunological studies of factor VIII coagulant activity (VIII:C). I. Assays based on a haemophilic and an acquired inhibitor to VIII:C. Thromb Res 1981;21:431-45.

${ }^{14}$ Farrugia A. Studies on the procurement of blood coagulation factor VIII. Edinburgh: University of Edinburgh, 1984. PhD Thesis.

${ }^{20}$ Gornall AG, Bardswill CJ, David MM. Determination of serum proteins by means of the Biuret reaction. J Biol Chem 1949; 177:751-66.

${ }^{21}$ Watt JG. Plasma fractionation. Clin Haematol 1976;5:95-112.

22 Over J, Bouma BN, Van Mourik JA, Sixma JJ, Vlooswijk R, Bakker-Woudenberg I. Heterogeneity of human factor VIII. I. Characterization of factor VIII present in the supernatant of cryoprecipitate. J Lab Clin Med 1978;91:32-46.

${ }^{2 s}$ Hershgold EJ, Pool JG, Pappenhagen AR. The potent antihaemophilic globulin concentrate derived from a cold insoluble fraction of human plasma: characterization and further data on preparation and clinical trial. J Lab Clin Med 1966;67:23-32.

Requests for reprints to: Dr C Prowse, Blood Transfusion Centre, Royal Infirmary, Edinburgh EH3 9HB, Scotland. 